\title{
Comparative Cost Analysis Of Intravenous And Subcutaneous Administration Of Rituximab In Lymphoma Patients
}

This article was published in the following Dove Press journal: ClinicoEconomics and Outcomes Research

\author{
Olga Delgado Sánchez $\mathbb{D}^{\prime}$ \\ Antonio Gutiérrez ${ }^{2}$ \\ Fernando do Pazo' \\ Jordi Ginés ' \\ Clara Martorell' \\ Bàrbara Boyeras' \\ Leyre Bento (iD) ${ }^{2}$ \\ Marta Garcia-Recio 2 \\ Antonia Sampol iD ${ }^{2}$ \\ 'Pharmacy Department, Son Espases \\ University Hospital, IdISBa, Palma, Spain; \\ ${ }^{2}$ Lymphoma Unit of Hematology \\ Department, Son Espases University \\ Hospital, IdISBa, Palma, Spain
}

\begin{abstract}
Purpose: The availability of different routes of administration of rituximab, with different dosing and times of infusion in the day care unit, raises the question of which formulation would be the best in terms of direct cost, particularly with the approval of new intravenous (IV) rituximab biosimilars. We aim to retrospectively compare the direct costs of IV and subcutaneous (SC) rituximab in lymphoma, considering drug cost, pharmacy handling and occupation in day care unit in Son Espases University Hospital during 2017, now that the IV biosimilar is available.
\end{abstract}

Patients and methods: The data were collected from Oncosafety ${ }^{\mathbb{R}}$-AVIDA for doses and SAP $^{\circledR}$ for economic data. The costs of occupation are published by the Local Health Service. Results: In 2017, 527 cycles were prescribed for 103 patients with lymphoma: $141 \mathrm{IV}$ and $386 \mathrm{SC}$. Median doses were $690 \mathrm{mg}$ and $1400 \mathrm{mg}$ with a median cost of the drug of $1458.45 €$ and $1334.77 €$ for IV and SC routes, respectively. The nurse handling costs were $4.49 €$ and $2.24 €$, respectively. The cost of the day care unit occupation was $493 €$ and $123 €$, respectively. Overall, the median total cost per cycle was $1955.94 €$ for the IV, $1460.01 €$ for the SC and $1729 €$ for the biosimilar $(\mathrm{p}<0.001)$. The sensitivity analysis showed that it would be necessary for the cost of the IV biosimilar to be $34 \%$ lower than the price of SC rituximab to make a difference.

Conclusion: This study shows a reduction in the cost with the administration of SC rituximab in real life compared with using the IV original rituximab and the biosimilar. This information is relevant for healthcare managers and administrations and applies only in the case of drugs with SC original presentations still not available in their correspondent biosimilars.

Keywords: cost analysis, rituximab, intravenous, subcutaneous, biosimilar

\section{Introduction}

Rituximab is a chimeric monoclonal antibody directed specifically against the CD20 antigen and approved, among others, for the treatment of lymphoma. Currently, it is available as both intravenous (IV) and subcutaneous (SC) formulations. The SC formulation combines rituximab with recombinant human hyaluronidase (rHuPH20) that increases tissue permeability through transient depolymerization of hyaluronic acid and allows SC administration of larger volumes. SC rituximab has shown equivalent clinical activity and safety compared to the IV formulation. ${ }^{1}$

Formulations of rituximab differ in concentration and dosing: while intravenously it is administered at $375-500 \mathrm{mg} / \mathrm{m}^{2}$, the SC route uses a fixed dose of 1400
Correspondence: Olga Delgado Sánchez Pharmacy Department, Son Espases University Hospital, Ctra. Valldemossa, 79 07I 20, Palma, Illes Balears, Spain

Tel +34-87। 205187

Email olga.delgado@ssib.es 
mg. Both formulations are administered in the OncoHematology Day Care Unit under medical supervision. IV infusions must be slow and well controlled, with progressive increments in the infusion rate to a maximum of $400 \mathrm{mg} / \mathrm{hr}$. In contrast, the administration of SC formulations takes only 5-7 mins. To receive the SC rituximab formulation, patients must have tolerated at least one previous IV dose.

The availability of different routes of administration of rituximab, with different dosing and times of infusion in the day care unit, raises the question of which formulation would be the best in terms of direct cost. Several studies have demonstrated a better pharmacoeconomic profile for the SC against the IV formulation. ${ }^{2,3,4}$ However, all of them were published before the approval of the IV rituximab biosimilar, which generated a reduction in the price of the IV drug formulation.

The aim of the study is to compare the direct costs associated with the use of IV and SC rituximab, not only considering the drug price but also the costs of pharmacy handling, place occupation and administration in the day care unit. Lately, we performed a sensitivity analysis to determine whether the results could be modified with the availability of the new IV biosimilar of rituximab and an exploratory analysis in a nonlymphoma group.

\section{Materials And Methods Study Design And Variables}

This is a retrospective study of direct costs associated with the use of IV or SC rituximab in adult patients with lymphoma, administered following the local standard practice in the day care unit of Son Espases University Hospital, the third-level reference hospital of Balearic Islands, during 2017. Among the variables evaluated for each patient, we included diagnosis, service, number of administrations for each formulation, IV doses, time of infusion as well as costs of the drug, pharmacy handling and occupation and infusion in the day care unit. We planned to perform:

- A description of all rituximab doses administered in 2017, including lymphoma and nonlymphoma indications

- A comparison of total cost and potential overruns related to IV and SC formulations, including the price of the drug but also the costs of the pharmacy nurse handling and the occupation of the day care.
- An estimation of the savings or overruns if all the previous doses would have been administered using the new IV biosimilar of rituximab, compared to IV or SC Mabthera ${ }^{\circledR}$.

- A sensitivity analysis to find out the reduction in the cost of the new IV biosimilar of rituximab to compensate for the overrun associated with IV presentation.

\section{Data Collection}

Data were obtained from the databases of the Pharmacy Department (Oncosafety ${ }^{\circledR}$-AVIDA software), allowing us to know the infusion time of each IV administration in real time from the infusion pumps of the day care unit. To estimate the occupation of the day care unit, we rounded off the infusion time recorded from the infusion pump and added $1 \mathrm{hr}$ to take into account the preparation of the patient and the time after the infusion until discharge.

Economic data were obtained from the SAP ${ }^{\circledR}$ management software. Expenses related to the drug are the median real price of acquisition of the drug per cycle in our setting (including negotiated price, discounts and VAT) in 2017. The costs of occupation of the day care unit are those officially published by the Local Health Service in January 2018 (Official Publication Balearic Island Government BOIB 16 September 2018), which establishes the official price of every cycle of chemotherapy administration considering its duration from $1 \mathrm{hr}$ to $6 \mathrm{hrs}$. To calculate the costs from the preparation of both drugs, we estimated the handling time of the pharmacy nurses of 5 mins for every dose of SC rituximab injection and 10 mins for the IV rituximab infusion, taking the price of $1 \mathrm{hr}$ of nursing work as $26.92 € / \mathrm{hr}$ from the Personnel Department.

\section{Data Analysis And Statistical Methods}

We performed a descriptive presentation of the main characteristics of the patients and doses administered during 2017. Qualitative variables were described as frequencies and percentages. Quantitative variables were expressed as median and ranges. Comparison between variables was made using the nonparametric $U$ of Mann-Whitney test, including cost per cycle, day care hospital cost per cycle and total cost per cycle between IV and SC formulations. All $\mathrm{p}$ values reported were 2 -sided, and statistical significance was defined at $\mathrm{p}<0.05$.

\section{Ethics Statement}

The data were obtained from pharmacy pharmacoeconomic records of 2017 in a fully anonymized and de-identified 
manner, and none of the researchers/authors had access to identifying information. Additionally, this work does not evaluate or consider any particular information (ie, demographics or outcomes) from medical records of this series. For these reasons, the research did not require review and approval from the research ethics committee, as it was stated by the reference IRB (CEI Illes Balears) with the number IB 4014/19.

\section{Results}

\section{Characteristics Of The Patients And Rituximab Doses Administered}

From 2 January 2017 to 29 December 2017, a total of 742 doses of rituximab were administered to 189 adult patients for all indications, of which 105 patients had lymphomas that received 541 cycles (average of 5,1 cycles per patient). Excluding the 14 doses administered via intrathecal route, and the two patients who only received intrathecal rituximab during the period, 527 cycles remain for the present study: $141 \mathrm{IV}$ and $386 \mathrm{SC}$ in 103 patients. The median weight was $70 \mathrm{~kg}(48-130)$ and the median body surface was $1.75 \mathrm{~m}^{2}(1.41-2.46)$. The median IV and SC doses were $690 \mathrm{mg}$ (530-920) and $1400 \mathrm{mg}$, respectively. The median infusion time for IV rituximab was $3.3 \mathrm{hrs}$ (1-5.9).

On the other hand, 84 patients received 201 cycles of rituximab for all other indications not related to lymphoma, mainly for autoimmune disorders and mostly IV (98\%). Median IV dose and infusion time for IV rituximab in these nonlymphoma indications was $1000 \mathrm{mg}$ (500-1000) and $3.8 \mathrm{hrs}(1-6.28)$. Table 1 shows the diagnosis of the two cohorts of patients.

\section{Costs Related To IV And SC Administration Of Rituximab In Lymphoma Therapy}

In 2017, the price that our hospital paid for $500 \mathrm{mg}$ IV vial presentation of rituximab (Mabthera ${ }^{\circledR}$ ) was $1056.85 €$ and for $1400 \mathrm{mg} \mathrm{SC}$ vial of rituximab, it was $1334.77 €$. In that year, a total of $97,156 \mathrm{mg}$ of IV rituximab was administered in 141 cycles for all lymphoma indications, with a median cost per IV cycle of $1458.45 €(1120-1944)$ compared to the fixed cost by cycle of the SC formulation of $1334.77 €$. This represents a median saving of $123.68 €(-214.51$ to 609.83$)$ per cycle in favor of the SC presentation $(-8.5 \%)$, only considering the cost of the drug $(\mathrm{p}<0.001)$.

As shown in Table 2, the costs of the pharmacy nurse handling for the preparation of the IV and SC presentations
Table I Diagnosis Of The Patients

\begin{tabular}{|l|l|l|}
\hline Lymphoma Patients & $\begin{array}{l}\text { Patients } \\
\text { (N) }\end{array}$ & $\begin{array}{l}\text { Cycles } \\
\text { (N) }\end{array}$ \\
\hline Diffuse large B-cell lymphoma, NOS & 44 & 208 \\
Follicular lymphoma & 31 & 160 \\
Burkitt lymphoma & 3 & 12 \\
Mantle cell lymphoma & 6 & 36 \\
MALT lymphoma & 6 & 41 \\
Lymphoplasmacytic lymphoma & 3 & 10 \\
Chronic lymphocytic leukemia & 3 & 18 \\
Splenic marginal zone lymphoma & 2 & 13 \\
Nodal marginal zone lymphoma & 2 & 9 \\
Peripheral T-cell lymphoma & 1 & 2 \\
Hodgkin lymphoma & 1 & 4 \\
Hairy cell leukemia & 1 & 14 \\
Total & 103 & 527 \\
\hline Nonlymphoma patients & Patients (N) & Cycles (N) \\
Systemic lupus & 18 & 39 \\
Other nonspecified systemic & 20 & 49 \\
autoimmune disorders & & \\
Rheumatoid arthritis & 6 & 16 \\
Vasculitis & 4 & 7 \\
Multiple sclerosis & 5 & 10 \\
Optic neuromyelitis & 5 & 12 \\
Scleroderma & 4 & 14 \\
Thrombotic thrombocytopenic & 4 & 13 \\
purpura & 3 & 6 \\
Graft rejection after organ transplant & 2 & 30 \\
Immune thrombocytopenic purpura & 13 & 201 \\
Other & 84 & \\
Total & & \\
\hline & & \\
\hline
\end{tabular}

Abbreviation: MALT, mucosa-associated lymphoid tissue.

were $4.49 €$ and $2.24 €$ per cycle, respectively. In the study, the total costs related to the pharmacy nurse handling for all lymphoma indications were $633.09 €$ for the $141 \mathrm{IV}$ cycles and $864.6 €$ for the $386 \mathrm{SC}$ cycles. The median time of occupation of the day care unit in the IV presentation for all lymphoma indications was $4 \mathrm{hrs}(1-7)$ that represented a median cost of $493 €(123-861)$. In the case of the SC presentation, the injection takes $10 \mathrm{mins}$, but our standard practice is to reserve $1 \mathrm{hr}$ in the day care unit $(123 €)$ for the preparation and discharge of the patient.

Overall, the median total cost per cycle (drug, preparation and day care unit occupation) was 1955.94€ (1290.032563.09) for each IV cycle versus a fix cost of $1460.01 €$ for the SC cycles $(\mathrm{p}<0.001)$ (median saving of $495.93 € /$ cycle $(-169.98$ to -1103.08$) ;-25.4 \%(-13$ to -43$)(p<0.001))$. The total annual cost for rituximab in lymphoma treatment during 2017 was $276,416.26 €$ for the 141 cycles of IV 
Table 2 Costs Associated With Intravenous (IV) And Subcutaneous (SC) Rituximab In Lymphoma Patients

\begin{tabular}{|c|c|c|c|c|c|}
\hline Rituximab & IV & SC & Difference & $\%$ & $\mathbf{p}$ \\
\hline Dose & $375-500 \mathrm{mg} / \mathrm{m} 2$ & $1400 \mathrm{mg}$ & & & \\
\hline Median real dose $2017(\mathrm{mg})$ & 690 & 1400 & & & \\
\hline Cycles & $|4|$ & 386 & & & \\
\hline Commercial price $(€)$ & $\begin{array}{l}\text { Rituximab } 500 \mathrm{mg} \text { IV } \\
\text { I056.85 }\end{array}$ & $\begin{array}{l}\text { Rituximab | } 400 \mathrm{mg} \mathrm{SC} \\
\text { | } 334.77\end{array}$ & & & \\
\hline Average drug cost per cycle $(€)$ & 1458.45 & 1334.77 & -123.68 & $-8.5 \%$ & $<0.001$ \\
\hline Preparation time (mins) & 10 & 5 & & & \\
\hline Cost per I hr nurse handling time $(€)$ & 26.92 & 26.92 & & & \\
\hline Handling time per cycle $(€)$ & 4.49 & 2.24 & & & \\
\hline Median day care hospital administration time & $4(I-7)$ hours & $\mathrm{I} \mathrm{hr}$ & & & \\
\hline Day care hospital cost per cycle & $493 €(|23-86|)$ & $123 €$ & & & $<0.001$ \\
\hline Total cost per cycle $(€)$ & $1955.94(\mid 290.03-2563.09)$ & $|460.0|$ & -495.93 & $-25.4 \%$ & $<0.001$ \\
\hline Total cost & $276,416.26$ & $563,563.86$ & & & \\
\hline
\end{tabular}

rituximab and $563,563.86 €$ for 386 injections of SC rituximab, with a total budget impact of $839,980.12 €$. Furthermore, we have calculated a cost overrun if all the cycles would have been administered with the IV presentation of $261,355.11 €$, which represents a $34 \%$ increase compared to the cost overrun if all the cycles would have been using the SC presentation.

\section{Cost Analysis Considering The New Rituximab Biosimilar}

We tested the same analysis using the new IV biosimilar of rituximab that currently represents a saving per cycle of $163.77 €(15 \%)$ with respect to the IV original drug (Mabthera $\left.{ }^{\circledR}\right)$ and is even cheaper than SC rituximab $(-9 \%)$. This translates into a presumed median total cost per cycle of 1792.17 when using the new IV biosimilar that would have represented a saving of $119,224.56 €(8 \%)$ with respect to IV Mabthera ${ }^{\circledR}$ but an overrun of $246,192.51$ (19\%) compared to SC for the 728 rituximab doses administered in our center in 2017 (including all lymphoma and nonlymphoma indications).
Table 3 shows the sensitivity analysis. In the studied population, for matching IV and SC costs, it would have been necessary for the costs of the IV presentation to be $34 \%$ lower than the price of the SC rituximab.

Costs Related To IV And SC Administration Of Rituximab In Nonlymphoma Patients

When making the same analysis for all the cycles administered to nonlymphoma patients $(n=201)$, the cost overrun for the IV rituximab compared to the SC presentation was calculated at 97,698.21€. Overall, if all 728 nonintrathecal rituximab infusions for all indications would have been administered using the SC presentation, the total savings for the hospital would have been $359,053.32 €$ compared with using IV rituximab in all cases. This illustrates the important budget impact of this infusion route.

\section{Discussion}

Our study shows a reduction in the cost of the drug, preparation and occupation of the day care unit associated

Table 3 Sensitivity Analysis With The Reduction Of The Price Of Intravenous (IV) Or Intravenous Biosimilar (IVbs) Versus Subcutaneous (SC) Presentations

\begin{tabular}{|l|l|l|l|l|l|l|}
\hline Route Of Administration & IV & IVbs & SC & IV & IV \\
\hline Discount (\%) & $0 \%$ & $0 \%$ & $0 \%$ & $-33 \%$ & $-34 \%$ & IV \\
Discount & 0 & 0 & 0 & -348.76 & -359.33 \\
Drug price (€) & 1056.85 & 893.08 & 1334.77 & 708.09 & 697.52 & -369.9 \\
Drug price per cycle (€) & 1458.45 & 1232.45 & 1334.77 & 977.16 & 962.58 & 686.95 \\
Preparation cost per cycle (€) & 4.49 & 4.49 & 2.24 & 4.49 & 4.49 & 447.99 \\
Administration cost per cycle $(€)$ & 493 & 493 & 123 & 493 & 493 & 4.49 \\
Total cost per cycle $(€)$ & 1955.94 & 1729.94 & 1460.01 & 1474.65 & 1460.07 \\
\hline
\end{tabular}


with the administration of SC rituximab in the real life of a third-level university hospital compared with the utilization of rituximab IV original but also in terms of occupation of the day care unit with rituximab biosimilar. Although several previous studies reported in part similar results with the original rituximab, with a decrease of more than $4 \%$ only of the direct costs of rituximab, and $44 \%$ in time reduction ${ }^{5}$ and more than $200,000 €$ saving per year for the hospital, ${ }^{6}$ no study has been made with the new biosimilar rituximab.

However, our study emphasizes the impact of the occupation of the day care unit that is not generally considered in the treatment cost analysis. The occupation cost is very relevant as it implies important expenses that translate into contracting more nurses or making them work more time. Alternatively, this problem could be overcome by delaying the treatment of several patients, but this is an unacceptable option as we believe that dose intensity is essential for the results of therapy in cancer patients. ${ }^{7,8}$

All the previously published studies show a better pharmacoeconomic profile of the SC presentations of rituximab and other multiple drugs, ${ }^{2-4,6,9,10}$ and the results are repeated in different countries and health systems. ${ }^{9,11,12-20}$ No known previous work showed higher costs related to SC presentations when compared to IV, so the results are very consistent, and the data have been extensively validated.

This evidence of lower costs related to SC administrations has promoted proactive strategies of change from IV to SC presentations in several hospitals ${ }^{18}$ and, additionally, in several countries, the development of studies of the potential budget impact of changing to SC presentations. ${ }^{21,22}$

Among the limitations of the study are the lack of randomization and the nonevaluation of efficacy and safety. Another limitation is the lack of analysis of the social costs associated with the traveling expenses or loss of productivity of the patient or caregivers; one study reported that $68 \%$ of the caregivers were active workers. ${ }^{6}$

Furthermore, in this study, patient preferences were not considered. The PrefMab and MabEASE studies estimated that $80-83 \%$ of patients preferred SC versus IV rituximab, due to a shorter time in the day care unit, a more comfortable administration and a lower emotional impact. ${ }^{23,24}$ Also, the evaluation of the nursing team was not taken into account where more than $94 \%$ prefer the $\mathrm{SC}$ route, ${ }^{3,25}$ or from the caregivers with $68 \%$ reported to prefer the SC presentation, ${ }^{3}$ and neither has the impact on the quality of life been analyzed in this study. One study showed that even though a better experience for the patient was reported, the quality of life was not modified. ${ }^{11}$

An advantage attributed to the $\mathrm{SC}$ presentation is a lower wastage of doses ${ }^{13}$ and a higher safety due to avoiding potential mistakes of dosage or preparation and infusion reactions - issues that have not been evaluated in the present work. ${ }^{3,26}$

In our hospital, there is no specific program of fast rituximab administration and the infusion time is our real-life time, which is similar to previously published studies ${ }^{12,18,27}$ and even shorter than in certain situations. ${ }^{16}$

Biosimilars represent an important way to save in healthcare management. They provide sustainability and must have the support of both private and public administrations. However, while our study demonstrates an important potential annual saving of $359,053,32 €$ from using SC rituximab when compared to infusing IV rituximab, this saving still remains even when considering the new IV biosimilar $(246,192.51 €)$, which the current discount in the price of the drug in our hospital (15\%) cannot compensate. We believe that this information is relevant for healthcare managers and administrations and applies only in the case of drugs with SC original presentations still not available in their correspondent biosimilars.

\section{Conclusion}

In conclusion, we can say that for all the indications analyzed, the administration of SC rituximab provides a shorter time of preparation, handling work and occupation of the day care unit, with a lower direct cost of the drug. For this reason, the $\mathrm{SC}$ route shows a better pharmacoeconomic profile than IV presentation. The introduction of rituximab biosimilar could modify the SC route favorable profile but only if the drug price is reduced by at least a $34 \%$ with respect to IV Mabthera ${ }^{\circledR}$, and this is only considering the economic data without taking into account the preferences of professionals, caregivers and patients.

In the future, it would be interesting to know the satisfaction of the patients, professionals and caregivers, as well as the possibility of administering SC rituximab at the patient's home if the treatment is in monotherapy, ${ }^{28}$ or in other nonlymphoma indications.

\section{Acknowledgement}

The authors thank Marcel Pla for the technical help and Jonathan McFarland for the translation assistance. 


\section{Disclosure}

ODS has been speaker to and has provided consultant services for Kern Pharma, Sandoz and Roche. AG discloses research support from Celgene, Janssen, Mundipharma and Roche and Scientific Advisory Boards to Celgene, Janssen, Mundipharma, Pfizer, Roche and Takeda. JG has been the speaker and has provided consultant services for Roche. $\mathrm{CM}$ reports personal fees and nonfinancial support from Roche, grants from BMS and personal fees from MSD, during the conduct of the study. The authors report no other conflicts of interest in this work.

\section{References}

1. Davies A, Merli F, Mihaljević B, et al. Efficacy and safety of subcutaneous rituximab versus intravenous rituximab for first-line treatment of follicular lymphoma (SABRINA): a randomised, open-label, phase 3 trial. Lancet Haematol. 2017;4(6):e272-82. doi:10.1016/ S2352-3026(17)30078-9

2. Franken MG, Kanters TA, Coenen JL, et al. Potential cost savings owing to the route of administration of oncology drugs: a microcosting study of intravenous and subcutaneous administration of trastuzumab and rituximab in the Netherlands. Anticancer Drugs. 2018;29 (8):791-801. doi:10.1097/CAD.0000000000000648

3. Tomarchio V, Surano MA, Tafuri MA, et al. Management, economic and social impact of sub-cutaneous rituximab administration in lymphoproliferative malignancies. Haematologica. 2017;06(102):298.

4. De Cock E, Kritikou P, Sandoval M, et al. Time savings with rituximab subcutaneous injection versus rituximab intravenous infusion: a time and motion study in eight countries. PLoS ONE. 2016;11 (6):e0157957. doi:10.1371/journal.pone.0157957

5. Di Rocco A, Scerbo G, Ansuinelli M, et al. Efficacy, safety and cost analysis of subcutaneous vs intravenous rituximab in patients with diffuse large B-cell lymphoma treated with RCHOP. Haematologica. 2017;10(102):110-111.

6. Annibali O, Tomarchio V, Becilli M, et al. Management, economic and social impact of sub-cutaneous Rituximab administration in diffuse large B cell lymphoma (DLBCL) and follicular lymphoma (FL). Haematol. 2017;Supl 3(102):113.

7. Gutiérrez A, Bento L, Bautista-Gili AM, et al. Differential impact of relative dose-intensity reductions in diffuse large B-cell lymphoma treated with R-CHOP21 or R-CHOP14. PLOS ONE. 2015;10(4): e0123978. doi:10.1371/journal.pone.0123978

8. Havrilesky LJ, Reiner M, Morrow PK, Watson H, Crawford J. A review of relative dose intensity and survival in patients with metastatic solid tumors. Crit Rev Oncol Hematol. 2015;93(3):203-210. doi:10.1016/j.critrevonc.2014.10.006

9. Renati L, Najun Dubos L. Cost analysis in implementing rituximab for non-hodgkins lymphoma - intravenously and subcutaneously - in patients with social coverage in Latam. Value Health J Int Soc Pharmacoeconomics Outcomes Res. 2015;18(7):A442-443. doi:10. 1016/j.jval.2015.09.1091

10. Wiesner C, De Cock E, Carella AM, Tao S. Potential time savings with rituximab subcutaneous (SC) injection versus rituximab intravenous (IV) infusion: results from interviews at 13 european sites as part of a time and motion study (T\&M). Value Health. 2012;15(7): A533. doi:10.1016/j.jval.2012.08.1856

11. Fargier E, Ranchon F, Huot L, et al. SMABcare study: subcutaneous monoclonal antibody in cancer care: cost-consequence analysis of subcutaneous rituximab in patients with follicular lymphoma. Ann Hematol. 2018;97(1):123-131. doi:10.1007/s00277-017-3147-y
12. Ponzetti C, Canciani M, Farina M, Era S, Walzer S. Potential resource and cost saving analysis of subcutaneous versus intravenous administration for rituximab in non-Hodgkin's lymphoma and for trastuzumab in breast cancer in 17 Italian hospitals based on a systematic survey. Clin Outcomes Res CEOR. 2016;8:227233.

13. Rauf M, Dada R, Awad N, Safwat M, Narang A, Goyal R. To determine the financial imapct of introducing SC rituximab (MABTHERA) vs. Currently Used IV Rituximab (MABTHERA) on the Budgets of Different Hospitals across the Kingdom of Saudi Arabia (KSA). Value Health 2017;20(9):A424.

14. Mihajlović J, Bax P, van Breugel E, et al. Microcosting study of rituximab subcutaneous injection versus intravenous infusion. Clin Ther. 2017;39(6):1221-1232.e4. doi:10.1016/j.clinthera.2017.05.342

15. Bax P, Postma MJ. Cost-minimization of mabthera intravenous versus subcutaneous administration. Value Health. 2013;16(7):A390A391. doi:10.1016/j.jval.2013.08.392

16. Nikolov O, Sterjev Z, Dimovski A, et al. Cost-minimization analysis of rituximab subcutaneous formulation versus intravenous administration of rituximab for the treatment of non-Hodgkin's lymphoma in the republic of Macedonia. Haematologica. 2017;06 (102):600.

17. Gomes G, Ho R, Rufino C, Alves M. Budget impact analysis of rituximab iv versus sc from public Brazilian hospital. Value Health. 2017;20(5):A98.

18. Irwin S, Rowntree C, Cosh H, Bloodworth C. Positive benefits of changing from intravenous Rituximab administration to subcutaneous administration: A single centre experience. Br J Haematol. 2017;03(176):68-69.

19. Rule S, Collins GP, Samanta K. Subcutaneous vs intravenous rituximab in patients with non-Hodgkin lymphoma: a time and motion study in the United Kingdom. J Med Econ. 2014;17(7):459-468. doi:10.3111/13696998.2014.914033

20. Saenz Ariza SA. Time and motion study for rituximab SC vs IV in colombian patients with non-hodgkin lymphoma. Value Health. 2015;18(5):A207. doi:10.1016/j.jval.2015.03.1200

21. Kulikov A, Rybchenko Y. Pharmacoeconomic study of the use of rituximab for subcutaneous administration in the treatment of follicular lymphoma. Value Health $J$ Int Soc Pharmacoeconomics Outcomes Res. 2015;18(7):A463.

22. Plommet N, Pau D, Tehard B. Economic evaluation and added value for stakeholders of switching from rituximab intravenous injection to rituximab subcutaneous injection in France. Value Health J Int Soc Pharmacoeconomics Outcomes Res. 2015;18(7):A664. doi:10.1016/j. jval.2015.09.2418

23. Rummel M, Kim TM, Aversa F, et al. Preference for subcutaneous or intravenous administration of rituximab among patients with untreated CD20+ diffuse large B-cell lymphoma or follicular lymphoma: results from a prospective, randomized, open-label, crossover study (PrefMab). Ann Oncol Off J Eur Soc Med Oncol. 2017;28 (4):836-842.

24. Lugtenburg P, Avivi I, Berenschot H, et al. Efficacy and safety of subcutaneous and intravenous rituximab plus cyclophosphamide, doxorubicin, vincristine, and prednisone in first-line diffuse large B-cell lymphoma: the randomized MabEase study. Haematologica. 2017;102(11):1913-1922. doi:10.3324/haematol.2017.173583

25. Assouline S, Buccheri V, Delmer A, et al. Pharmacokinetics, safety, and efficacy of subcutaneous versus intravenous rituximab plus chemotherapy as treatment for chronic lymphocytic leukaemia (SAWYER): a phase $1 \mathrm{~b}$, open-label, randomised controlled noninferiority trial. Lancet Haematol. 2016;3(3):e128-138. doi:10.1016/ S2352-3026(16)00004-1

26. MacDonald D, Crosbie T, Christofides A, Assaily W, Wiernikowski J. A Canadian perspective on the subcutaneous administration of rituximab in non-Hodgkin lymphoma. Curr Oncol Tor Ont. 2017;24 (1):33-39. doi: $10.3747 / \mathrm{co} .24 .3470$ 
27. Iuliano F, Iuliano E, Perricelli A, et al. Rituximab Subcutaneous Formulation (SC-R) is safe, effective and cost-saving in patients suffering from Autoimmune Hemolytic Anemia (AIHA). Blood. 2016;128(22):1269. doi:10.1182/blood-2016-06-724161
28. Wolfromm A, Mittaine B, Gandrille N, Dallemagne J, Delarue R. Home administration of subcutaneous rituximab is safe and associated with significant cost saving: a single center experience. Blood. 2017; Supplement 1:130.

\section{Publish your work in this journal}

ClinicoEconomics and Outcomes Research is an international, peerreviewed open-access journal focusing on Health Technology Assessment, Pharmacoeconomics and Outcomes Research in the areas of diagnosis, medical devices, and clinical, surgical and pharmacologica intervention. The economic impact of health policy and health systems organization also constitute important areas of coverage. The manuscript management system is completely online and includes a very quick and fair peer-review system, which is all easy to use. Visit http://www.dovepress.com/testimonials.php to read real quotes from published authors. 